Proceedings of the International Congress on Advances in Applied Physics and Materials Science, Antalya 2011

\title{
Sintering Behaviour of ZnO:Cu Ceramics Fabricated by Sol-Gel Derived Powders
}

\author{
Z.B. BAhŞI ${ }^{a}$, A.Y. ORAL ${ }^{a}$, M.H. Aslan ${ }^{b}$, E. KAYAHAN $^{c, d}$ AND M. OzER ${ }^{e}$ \\ ${ }^{a}$ Dept. of Materials Science and Engineering, Gebze Institute of Technology, 41400, Kocaeli, Turkey \\ ${ }^{b}$ Dept. of Physics, Gebze Institute of Technology, 41400, Kocaeli, Turkey \\ ${ }^{c}$ Gebze MYO, Kocaeli University, 41420, Kocaeli, Turkey \\ ${ }^{d}$ Natural and Applied Sci. Inst. Electro-optic and Sys. Eng. Umuttepe, Kocaeli University, 41380, Kocaeli, Turkey \\ ${ }^{e}$ Dept. of Physics, Istanbul Kultur University, 34156, Istanbul, Turkey \\ Doped zinc(II) oxide $(\mathrm{ZnO}: \mathrm{Cu})$ ceramics were prepared from sol-gel derived nanocrystalline powders. \\ Powders were prepared by dissolving zinc and copper acetates in isopropyl alcohol. Ethanolamine was used to \\ enhance the solubility of acetates. Powders were produced by the calcination of the dried gels at $750{ }^{\circ} \mathrm{C}$. The \\ crystal size of the undoped powders were uniform and around $50 \mathrm{~nm}$ while grain size of $\mathrm{Cu}$ doped powders \\ varied between 0.3 and $2 \mu \mathrm{m}$. X-ray mapping of the powders showed that $\mathrm{Cu}$ was not homogeneously distributed \\ and some particles had higher $\mathrm{Cu}$ content. After pressing of the powders, both doped and undoped ceramics \\ were sintered at $1200^{\circ} \mathrm{C}$ for $2 \mathrm{~h}$. Microstructure of the $\mathrm{Cu}$ doped ceramics showed that $\mathrm{Cu}$ atoms partially \\ dissolved in $\mathrm{ZnO}$ matrix and the rest formed a second phase in the grain boundaries. Average grain size of the \\ $\mathrm{ZnO}: \mathrm{Cu}$ ceramics was around $30 \mu \mathrm{m}$. Relative densities of the ceramics increased from 0.695 to 0.857 by Cu doping.
}

PACS: 81.05.Je, 81.05.Mh

\section{Introduction}

Nowadays zinc oxide is one of the most studied materials due to its potential applications such as optoelectronics and spintronics [1]. Single crystal and thin-film $\mathrm{ZnO}$ are attracting a great deal of interest for UV and blue light emitter applications. Sintered $\mathrm{ZnO}$ ceramics doped with $\mathrm{Bi}_{2} \mathrm{O}_{3}$ and other oxide additives are quite important as varistors $[2,3]$.

Different wet chemical methods have been applied to produce $\mathrm{ZnO}$ nanopowders [4-9]. Nanoparticles yield a narrow grain size distribution and excellent stability against grain growth. In addition, they can be sintered at lower temperatures than ceramics with larger grain size [6]. When semiconductors are prepared in the form of ultrafine particles, they experience great changes of properties, such as blue shift in absorption edge due to charge carrier confinement resulting in the widening of the band gap [5].

Due to its similar electronic shell structure, $\mathrm{Cu}$ has many physical and chemical properties similar to those of $\mathrm{Zn} \mathrm{[10].} \mathrm{The} \mathrm{solubility} \mathrm{of} \mathrm{Cu}$ in $\mathrm{ZnO}$ lattice is estimated to be around $1.0 \mathrm{~mol} \% \mathrm{Cu}$ [11]. It is well known that $\mathrm{Zn}^{2+}$ ions are substituted by $\mathrm{Cu}^{+}$ions in the $\mathrm{ZnO}$ lattice. Hall coefficient measurements have shown that number of carriers is reduced by $\mathrm{Cu}$ doping at room temperature since some of the $n$-type $\mathrm{ZnO}$ electrons occupies empty lower energy $3 d \mathrm{Cu}$ states leading to $\mathrm{Cu}^{+}$ions [12]. West et al. [13] proposed a donor-acceptor model for $\mathrm{Cu}_{\mathrm{zn}}$ where

$$
\begin{aligned}
& {\left[\mathrm{Cu}_{\mathrm{zn}}^{+}\left(3 d^{10}\right)\right]^{-}+\mathrm{Zn}_{\mathrm{i}}^{+}\left(4 s^{1}\right)} \\
& \quad \rightarrow\left\{\left[\mathrm{Cu}_{\mathrm{zn}}^{+}\left(3 d^{10}\right)\right] \mathrm{Zn}_{\mathrm{i}}^{+}\left(4 s^{1}\right)\right\}^{0}
\end{aligned}
$$

This model can be written in the Kröger and Vink notation as below [14]:

$$
\mathrm{Cu}_{\mathrm{zn}}^{\prime}+\mathrm{Zn}_{\mathrm{i}}^{\cdot} \rightarrow\left[\mathrm{Cu}_{\mathrm{zn}}+\mathrm{Zn}_{\mathrm{i}}\right]^{\mathrm{x}} \text {. }
$$

In present work, we report on the solitary effects of $\mathrm{Cu}$ doping, possible to be used as a doping element in varistors, on the microstructure and sintering behavior of $\mathrm{ZnO}$ ceramics prepared from sol-gel derived nanocrystalline powders. Varistor ceramics contain many doping elements to give a combined effect on microstructure and electrical properties and there have been many studies on the different varistor compositions. However, the separate effects of different doping elements on the microstructure of $\mathrm{ZnO}$ ceramics have been less frequently studied.

\section{Experimental}

The solutions were prepared by dissolving zinc acetate $\left(\mathrm{Zn}\left(\mathrm{CH}_{3} \mathrm{COO}\right)_{2} \cdot 2 \mathrm{H}_{2} \mathrm{O}\right)$ in isopropanol $\left(\mathrm{CH}_{3} \mathrm{CHOHCH}_{3}\right)$ and ethanolamine $\left(\mathrm{C}_{2} \mathrm{H}_{7} \mathrm{NO}\right)$. The final solutions, with concentrations of $4 \mathrm{M}$, were light brown and clear without any suspension of particles. Copper acetate $\left(\left(\mathrm{CH}_{3} \mathrm{COO}\right)_{2} \cdot \mathrm{Cu} \cdot \mathrm{H}_{2} \mathrm{O}\right)$ was added to the resulting solution to attain $\mathrm{Zn}: \mathrm{Cu}, 0.95: 0.05$ in the final ceramics. After mixing the doped solution for $20 \mathrm{~min}$ by using a magnetic stirrer, the solution was dried under open atmosphere for one week. Afterwards, the dried gels were calcinated at $750^{\circ} \mathrm{C}$ for $2 \mathrm{~h}$. Resulting powders were passed through a $30 \mu \mathrm{m}$ sieve to separate agglomerated particles during calcination. Then the fine powder was uniaxially pressed under $75 \mathrm{MPa}$. Finally, resulting ceramics were sintered at $1200^{\circ} \mathrm{C}$ for $4 \mathrm{~h}$. 


\section{Result and discussion}

\subsection{Analysis of sol-gel derived nanopowders}

X-ray diffraction (XRD) patterns of the undoped calcinated powders showed reflections solely belonging to zincite phase (Fig. 1a). $\mathrm{Cu}$ doped calcinated powders showed the same peaks, however, there were slight shifts in the peak positions towards the higher angle indicating reduction of the lattice parameters (Fig. 1b, Table). In addition, there were additional low intensity peaks identified to be belonging to tenorite $(\mathrm{CuO})$ phase.

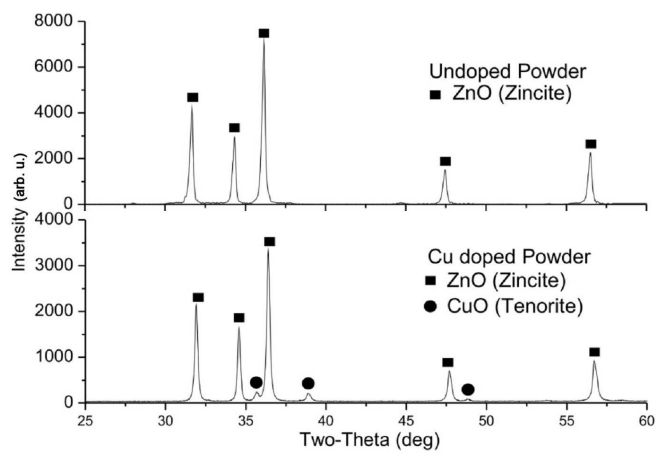

Fig. 1. XRD patterns of the (a) undoped, (b) $\mathrm{Cu}$ doped $\mathrm{ZnO}$ powders.

Scanning electron microscopy (SEM) micrograph of the powders showed that crystallite size of the undoped powders was around $50 \mathrm{~nm}$ and this value considerably increased in $\mathrm{Cu}$ doped powders to $0.3-2 \mu \mathrm{m}$ (Fig. 2). The spherical particles encountered in undoped powder are probably formed by the aggregation of nanosize crystallites (colloids) preexisting in the sol. The crystals in $\mathrm{Cu}$ doped powders seemed to have less isotropic shapes compared to undoped powders.

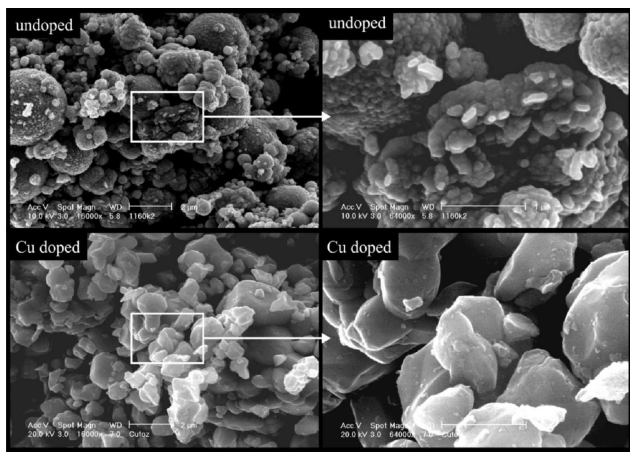

Fig. 2. SEM micrographs of undoped and $\mathrm{Cu}$ doped $\mathrm{ZnO}$ powders.

Figure 3 shows the X-ray mapping of $\mathrm{ZnO}: \mathrm{Cu}$ powders. There were some exaggerated grain growth in some of the crystals of $\mathrm{ZnO}: \mathrm{Cu}$ powders as it can be seen in the secondary electron image of the mapped area to reveal any composition difference between the smaller and
TABLE

Lattice parameters of the undoped and $\mathrm{Cu}$ doped $\mathrm{ZnO}$ powders and ceramics.

\begin{tabular}{c|c|c}
\hline \hline Sample & $a[\AA]$ & $c[\AA]$ \\
\hline ZnO (powder) & 3.248 & 5.199 \\
ZnO (ceramic) & 3.247 & 5.198 \\
$\mathrm{ZnO}: \mathrm{Cu}$ (powder) & 3.233 & 5.179 \\
$\mathrm{ZnO}: \mathrm{Cu}$ (ceramic) & 3.233 & 5.181 \\
JCPDS 36-1451 & 3.249 & 5.206
\end{tabular}

larger crystals. Mapping was applied to the area of the powder comprising both types of the crystals. Since the amount of the X-rays reaching the detector is also affected by the topological differences in the powders. In addition to composition, the comparison was made by using the intensity difference between all mapped elements (i.e. zinc, oxygen and copper). There was no apparent difference between the zinc and oxygen concentrated areas regardless of the size of the crystals. There were some small of $\mathrm{Cu}$ concentrated areas indicating that tenorite phase had a very small crystal size. The rest of the powders had homogeneously distributed $\mathrm{Cu}$ among the other crystallites of the powder. Exaggeratedly grown crystals did not display any compositional difference.

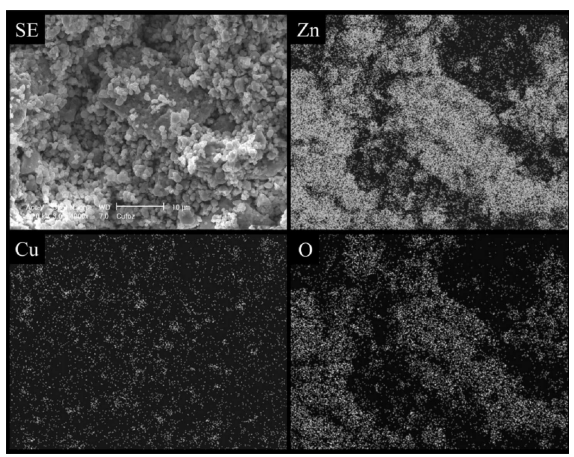

Fig. 3. X-ray mapping of the $\mathrm{Cu}$ doped $\mathrm{ZnO}$ powder.

\subsection{Effects of doping on microstructure and sintering behavior}

XRD patterns of the ceramics were similar to XRD patterns of powders (Fig. 4a, b). Accordingly, both lattice parameters $(a$ and $c$ ) of the zincite structure decreased after $\mathrm{Cu}$ doping which can be an evidence for substitution of some $\mathrm{Cu}^{++}$(ionic radius of $\mathrm{Cu}^{++}=0.073 \mathrm{~nm}$ ) on $\mathrm{Zn}$ lattice sites (ionic radius of $\mathrm{Zn}^{2+}=0.074 \mathrm{~nm}$ ) (Table).

Figure 5 shows the SEM micrographs of the ceramics. The results showed that the grain size of the undoped ceramics was distributed in the range $2-10 \mu \mathrm{m}$ while the grain size of the $\mathrm{Cu}$ doped ceramics was considerably larger and was between 10 and $40 \mu \mathrm{m}$ (Fig. 5). There were pores in both doped and undoped ceramics. However, the number of the pores in the pure $\mathrm{ZnO}$ ceramics 


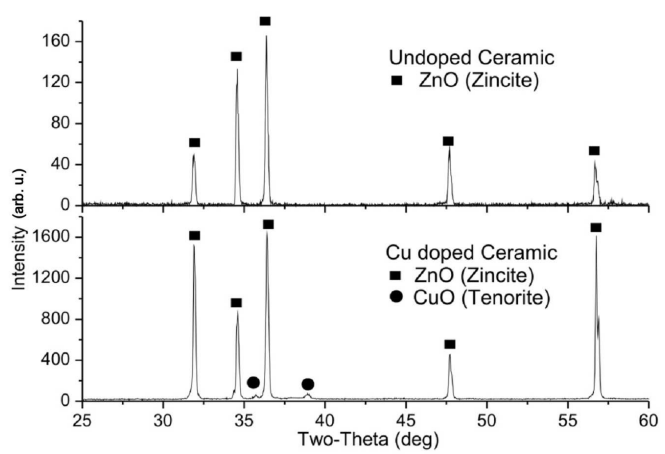

Fig. 4. XRD patterns of the (a) undoped, (b) $\mathrm{Cu}$ doped $\mathrm{ZnO}$ ceramics.

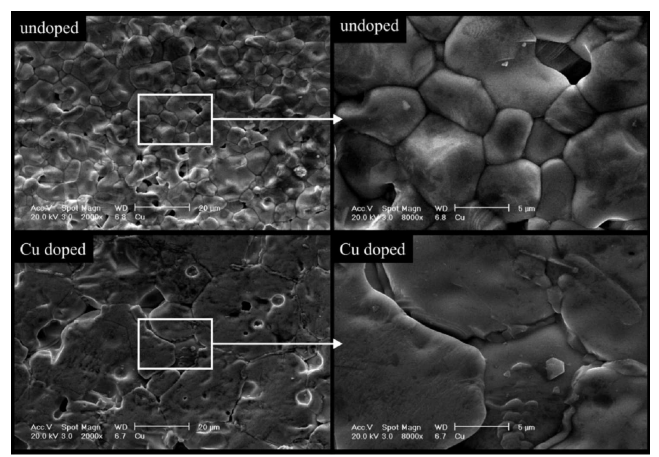

Fig. 5. SEM micrographs of undoped and $\mathrm{Cu}$ doped $\mathrm{ZnO}$ ceramics.

was higher. In addition, the pores in the pure ceramics were between the grains indicating that sintering had not been completed due to low diffusional mobility. The most of the pores present in the $\mathrm{ZnO}: \mathrm{Cu}$ ceramics were within the grains which showed that grain growth had began before the completion of pore shrinkage.

$\mathrm{X}$-ray mapping of the $\mathrm{Cu}$ doped ceramics showed the presence of second phase (tenorite phase observed in $\mathrm{XRD}$ results). $\mathrm{Zn}$ and $\mathrm{Cu}$ maps showed that tenorite phase was segregated in the grain boundaries (Fig. 6). Oxygen map did not show any difference between the two phases and supported the XRD results $(\mathrm{CuO}$ vs. $\mathrm{ZnO})$.

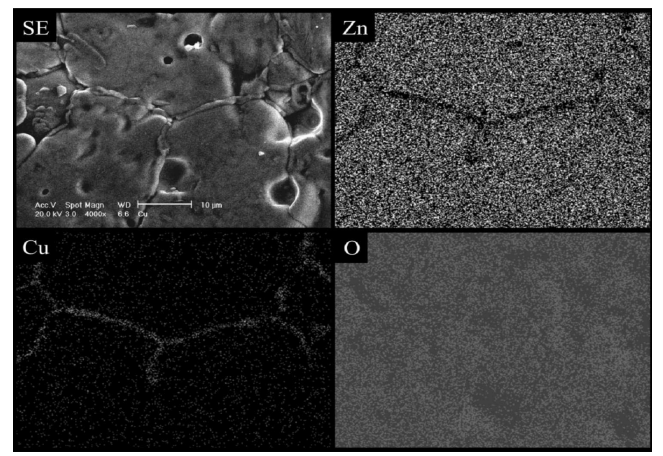

Fig. 6. X-ray mapping of the $\mathrm{Cu}$ doped $\mathrm{ZnO}$ ceramics.

\section{Conclusions}

1. $\mathrm{ZnO}: \mathrm{Cu}$ ceramics $(\mathrm{Zn}: \mathrm{Cu}, 0.95: 0.05)$ have been successfully fabricated from sol-gel derived nanocrystalline powders and relative densities of the ceramics increased from 0.695 to 0.857 by $\mathrm{Cu}$ doping after sintering at $1200^{\circ} \mathrm{C}$.

2. $\mathrm{Cu}$ doped powders showed increased crystalline size compared to undoped powders.

3. Compared to the undoped $\mathrm{ZnO}$, the lattice parameters of both $\mathrm{Cu}$ doped powders and ceramics decreased.

4. Both doped powders and doped ceramics showed the presence of tenorite phase. The second phase was segregated in the grain boundaries in the ceramics while it formed separate tenorite crystals in the powders.

\section{References}

[1] E. Rita, E. Alves, U. Wahl, J.G. Correia, T. Monteiro, M.J. Soares, A. Neves, M. Peres, Nucl. Instrum. Methods Phys. Res. B 242, 580 (2006).

[2] W. Jo, S.J. Kim, D.Y. Kim, Acta Mater. 53, 4185 (2005).

[3] T.K. Gupta, J. Am. Ceram. Soc. 73, 1817 (1990).

[4] K. Ya, H. Yin, T.M. De, T.M. Jing, Mater. Res. Bull. 33, 1703 (1998).

[5] L. Jing, Z. Xu, J. Shang, W. Cai, H. Guo, Mater. Sci. Eng. A 332, 356 (2002).

[6] K.X. Ya, W.T. Diao, H. Yin, T.M. De, T.M. Jing, Mater. Res. Bull. 32, 1165 (1997).

[7] Y. Lin, Z. Zhang, Z. Tang, F. Yuan, J. Ki, Adv. Mater. Opt. Electron. 9, 205 (1999).

[8] Y.Q. Huang, L. Meidong, Z. Yike, L. Churong, X. Donglin, L. Shaobo, Mater. Sci. Eng. B 86, 232 (2001).

[9] S. Bandyopadhyay, G.K. Paul, R. Roy, S.K. Sen, S. Sen, Mater. Chem. Phys. 74, 83 (2002).

[10] S.M. Zhou, X.H. Zhang, X.M. Meng, K. Zou, X. Fan, S.K. Wu, S.T. Lee, Nanotechnology 15, 1152 (2004).

[11] J.V. Bellini, M.R. Morelli, R.H.G.A. Kiminami, Mater. Lett. 57, 73325 (2003).

[12] X. Feng, J. Phys., Condens. Matter 16, 4251 (2004).

[13] C. West, D.J. Robbins, P.J. Dean, W. Hayes, Physica 116B, 492 (1983).

[14] J.V. Bellini, M.R. Morelli, R.H.G.A. Kiminami, J. Mater. Sci., Mater. Electron. 13, 485 (2002). 